\title{
DECISION MAKING FOR THE VALUATION OF ITAIPU'S ENERGY IN THE BRAZILIAN MARKET: AN APPROACH BASED ON AHP
}

\begin{abstract}
The production of clean electrical energy has acquired a preponderant role in energy security in recent decades. This is the case of the Itaipu Binational Hydroelectric Plant, which takes advantage of one of the resources that Paraguay has in condominium with Brazil. This power plant satisfies almost all of Paraguay's electric power demand, and there are even surpluses of energy that, under what is regulated in the binational Treaty, are ceded to the condominium country. In recent years, in Paraguay, an interesting debate has been generated about what would be the best use of this surplus energy. One of the alternatives is the sale of said Paraguayan energy in the Brazilian electricity market. For this purpose, an important input in the analysis of this strategy would be the valuation of Itaipu's energy. However, at present, there is no mechanism for the valution of such energy. The only valuation available is the Itaipu energy tariff and the compensation for the energy transfer, based exclusively on the conditions defined in the Treaty. Therefore, the methodology of the Analytic Hierarchy Process (AHP) is used to develop this approach. This technique is applied in multicriteria decision-making process and can be used for asset valuation. In this case, the objective of this work is to estimate or appreciate the value of Itaipu's energy. The attributes for the development of the AHP, that is, technical, economic and environmental aspects, are prioritized according to their degree of importance. Finally, the alternatives are valued through a benchmarking with the Brazilian hydroelectric power plants. Subsequently, a sensitivity analysis is carried out among the alternatives analyzed, in order to observe the variation of the results obtained.
\end{abstract}

Keywords: Itaipu power plant, electric power, valuation, AHP.

\section{Introduction}

The global economic integration of the last decades has been based on the creation of common markets, in which countries can market their goods without borders. In the same way, the liberalization of the energy markets has taken place at the same time, in search of the creation of an Integrated Electricity Market. For its part, the energy sector in Paraguay differs from other countries, due to the existing capacity of hydroelectricity. This renewable energy, accompanied by sustainable planning, should be the cornerstone 
of an energy policy that drives the country's economy. Thus, Paraguay must take advantage of the high level of hydroelectricity available, by promoting the use of hydroelectricity or commercializing it in third countries.

In this sense, a great debate has been created in Paraguay, on the use of the surplus energy of the Itaipu Power Plant, as well as its possible commercialization in third electricity markets (Agreement of Presidents, 2009, to commercialize Paraguayan energy in Brazil), and the value of said energy. Thus, the different analyzes have been characterized by the conflict of existing interests, be they economic, technical, environmental, etc. Therefore, it requires examining support methodologies for the assessment of energy, moreover, where multiple criteria are involved in decision making. For the proper analysis of this type of problem, a large number of multicriteria assessment methods have been developed in recent decades. In this sense, perhaps one of the most widespread methods is the Analytic Hierarchy Process (AHP), which is known as a methodology for the treatment of complex decisions, developed by Thomas Saaty. In this context, the various analyzes carried out on the valuation of Itaipu's energy have generated a lot of uncertainty. Therefore, multi-criteria decision-making for the valuation of Itaipu energy is a key aspect that must be considered for the analysis.

This paper analyzes several alternatives of power plants. These alternatives are studied under multiple evaluation criteria. With these considerations, it is intended to provide decision makers with an assessment tool, in order to have an analytical support in their negotiation strategies and, in this way, to take a well-founded decision that produces the greatest benefits and help find a roadmap for the sustainable development of Paraguay.

\section{Literature Review}

Currently, the AHP is used in the process of estimating a value, in the valuation of assets or financial assets and in the appraisal of athletes. Likewise, the AHP is used in multicriterial agrarian valuation (J. A. Bellver , 2007), in the valuation of companies (E. Guijarro, 2009), in processes of property pricing (J. Aznar, 2010) and in the social valuation of peri-urban agrarian systems (I. Marques Perez, 2014). In addition, it should be mentioned that Paraguay does not currently have a valuation methodology for Itaipu's electric power in the Brazilian electricity market. Therefore, the use of AHP has been proposed as a methodology for valuing said energy.

\section{Hypotheses/Objectives}

This work proposes to develop a model using the AHP technique, with the objective of estimating the value of Itaipu's electric power in the Brazilian electricity market.

\section{Research Design/Methodology}

For this research work, the alternatives considered in the case study are evaluated according to several evaluation criteria, such as: Environmental Impact, Plant Factor, 
Installed Capacity, Operational Flexibility and Reliability. It can be seen in Figure 1, the hierarchy of the decision used in the Itaipu electric power valuation process.

Environmental Impact: the indicator considered is the emission of greenhouse gases, methane $\left(\mathrm{CH}_{4}\right)$. The emission of gases from each hydroelectric plant is proportional to the reservoir area of each of them. This assumption has been used to perform the pairwise comparison of the alternatives.

Plant Factor: the indicator of this criterion shows the capacity of a power plant to use over time. The calculation is given by the following equation:

$$
P F=\text { Power generated / Installed capa city }
$$

For the calculation of this criterion, data of electric power generation of the plants evaluated as alternatives were used. In addition, installed power data from the same plants have been used to perform the pairwise comparison of the alternatives.

Installed Capacity: this indicator represents the nominal capacity of electric power generation. For the analysis of this evaluation criterion, data of installed capacity of each power plant were considered to perform the pairwise comparison of the alternatives.

Operational Flexibility: the indicator of this criterion reveals the capacity of each power plant to respond immediately to fluctuations in electricity demand. Firstly, it should be noted that the AHP methodology allows the introduction of qualitative and quantitative variables that other methods do not allow. Thus, qualitative variables become quantitative because they are quantified through their own vectors. For this criterion, the weighting was carried out qualitatively (based on quantitative indicators), through judgments of experts in the energy area. The hydroelectric dams with reservoirs offer incomparable operational flexibility since they can respond immediately to fluctuations in electricity demand. Therefore, the reservoir area of each hydroelectric plant has been used to perform the pairwise comparison of the alternatives.

Reliability: this indicator corresponds to the availability of a generating unit or a power plant, and refers to the time in which said power plant is able to provide service. The loss of generation capacity associated with the faults depends on the number of generating units that are out of service. The paired comparison of the alternatives was carried out qualitatively (based on quantitative indicators). Therefore, the alternatives were compared considering the number of generating units in operation of each plant.

The alternatives studied are the power plants considered comparable that are observed in the aforementioned figure. The alternatives are hydroelectric power plants that are in operation in the Brazilian electricity market. These plants were selected according to their importance in the operation of the Brazilian electric system. The alternatives are the following power plants: UHE Porto Primavera, UHE Ilha Solteira, UHE Tucuruí and, finally, the alternative analyzed as object of valuation is the $\mathrm{CH}$ Itaipu Binational.

\section{Data/Model Analysis}


Initially, the weighting of the evaluation criteria is carried out (considering the weights of the criteria equal to 1). The result of this comparison determines a matrix of weighting of said criteria. Then, the comparison by pairs of the analyzed alternatives is carried out according to each of the evaluation criteria. Finally, we obtain the weighting of the power plants according to each of the criteria. Weights of each alternatives and criteria were determined by a pool of experts in the area of energy in Paraguay, and validate by the calculation of the consistency index.

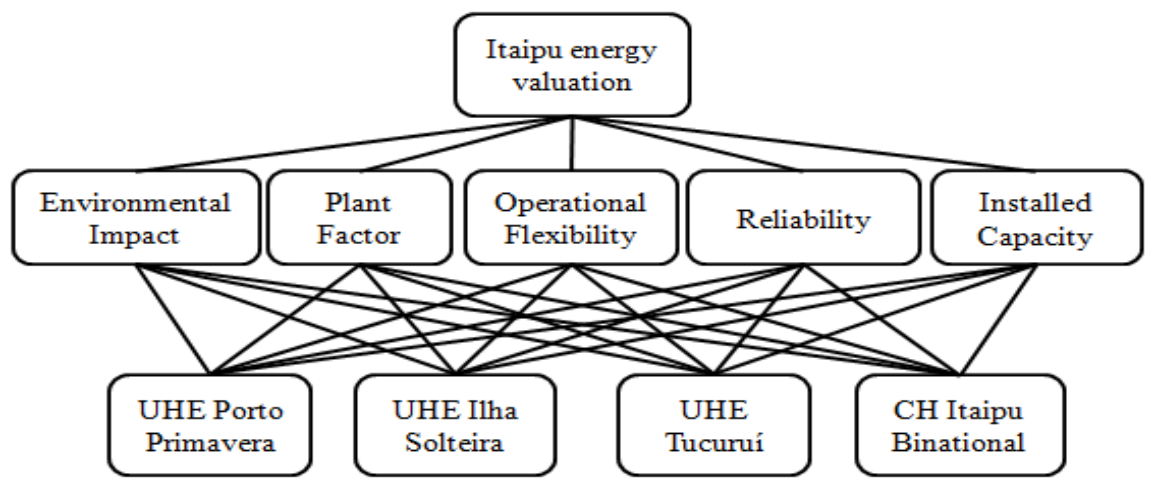

Fig. 1. Hierarchical tree

Finally, the results of the previous weights obtained are grouped to form the matrix of weights of alternatives. This matrix is multiplied by the matrix of weights of the criteria according to the main objective. The product of both matrices gives us as a result the global weighting matrix and the result can be seen in Figure 2.

$\left[\begin{array}{ccccc}0,1611 & 0,2767 & 0,30000,0960 & 0,0563 \\ 0,4658 & 0,2371 & 0,1000 & 0,1611 & 0,1259 \\ 0,0960 & 0,2006 & 0,4000 & 0,4658 & 0,3060 \\ 0,2771 & 0,2856 & 0,2000 & 0,2771 & 0,5118\end{array}\right] \times\left[\begin{array}{c}0,2000 \\ 0,2000 \\ 0,2000 \\ 0,2000 \\ 0,2000\end{array}\right]=\left[\begin{array}{c}0,1780 \\ 0,2180 \\ 0,2937 \\ 0,3103\end{array}\right]$

Fig. 2. Global weighting of power plants

Subsequently, once the global weight is calculated and, in addition, the values of the alternatives considered comparable are known, we proceed to calculate the ratio between the sum of both values. Therefore, the values of the energy sale price of Brazilian power plants are observable through the monthly publications of the Chamber of Electricity Commercialization (CCEE), see Table 1.

Table 1. Values of the energy sale price of the Brazilian market

\begin{tabular}{|l|c|c|}
\hline \multicolumn{1}{|c|}{ Comparable alternatives } & $\begin{array}{c}\text { Energy sale prices } \\
(\mathrm{R} \$ \mathrm{MWh})\end{array}$ & Global weighting of power plants \\
\hline UHE Porto Primavera & 213,49 & 0,1780 \\
\hline $\begin{array}{l}\text { International Symposium on the } \\
\text { Analytic Hierarchy Process }\end{array}$ & 4 & Hong Kong, HK.
\end{tabular}


ISAHP Article: A Style Guide for Paper Proposals To Be Submitted to the International Symposium on the Analytic Hierarchy Process 2018, Hong Kong, HK.

\begin{tabular}{|c|c|c|}
\hline UHE Ilha Solteira & 247,61 & 0,2180 \\
\hline UHE Tucuruí & 340,48 & 0,2937 \\
\hline SUM & 801,58 & 0,6897 \\
\hline
\end{tabular}

Finally, Itaipu's energy value is calculated through the product between the calculated ratio and the global weight that had been obtained previously for the Itaipu alternative. This process is detailed in Table 2 .

Table 2. Valuation process

\begin{tabular}{|c|c|c|}
\hline Ratio & $801,58 / 0,6897=1162,21$ & \\
\hline Value of the ITAIPU energy & $\mathbf{1 1 6 2 , 2 1} \times \mathbf{0 , 3 1 0 3}=$ & $\mathbf{3 6 0 , 6 4} \mathbf{R}$ \$MWh \\
\hline Exchange rate: & $1 \mathrm{R} \$=0.295937$ USD & \\
\hline & & $\mathbf{1 0 6 , 7 3} \mathbf{U S D} / \mathbf{M W h}$ \\
\hline
\end{tabular}

Therefore, considering the exchange rate expressed in the previous table, in addition to all the evaluation criteria and the realization of the benchmarking with the Brazilian power plants, the appreciation or the estimated value of the electric power of the Itaipu Hydroelectric Power Plant, according to the Brazilian market price is 106.73 USD/MWh.

\section{Sensitivity Analysis}

This analysis is carried out in order to examine the degree of sensitivity of the result obtained by varying the weight of the evaluation criteria. With this, you can observe the alterations of the results. To do this, different weightings have been given to the criteria with respect to their initial state and the valuation process has been carried out. Finally, in Figure 3 the variation of the estimation of Itaipu's energy value can be appreciated. With this variation you can see how it impacts on the methodology to allocate more weight to the evaluation criteria, considering their combinations.

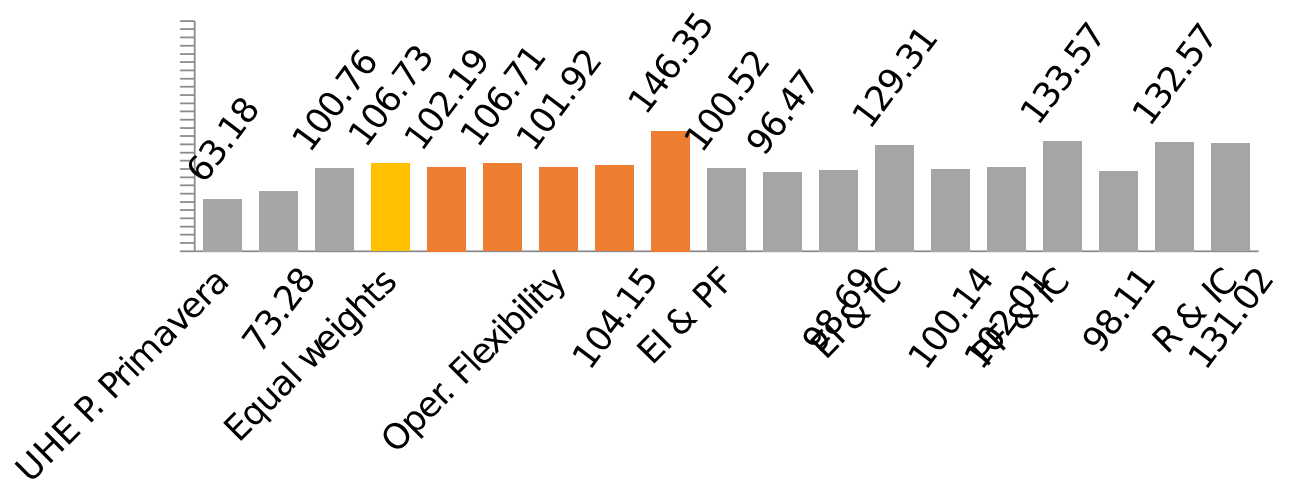

Fig. 3. Variation in the estimate of the value of Itaipu's energy (USD/MWh) 


\section{Limitations}

For future work it would be interesting to consider a larger sample of the alternatives to be analyzed. In addition, other generation technologies could be considered in the comparison by pairs (for example, thermal power plants).

\section{Conclusions}

The production of energy through Itaipu is one of the most important resources that Paraguay has and, therefore, should be valued adequately. The impact of an adequate valuation of Itaipu's energy could positively affect different areas, for example: increase in jobs, better education and greater investment in health. In this context, the valuation of Itaipu energy could be a complex task due to the different existing criteria. In this sense, this work has presented the AHP as a multicriteria valuation tool suitable for the case study. In addition, it is intended to provide to decision makers a tool with scientific rigor, with the analysis of a contemporary problem, in order to make informed decisions that will produce the greatest benefits for the country. Finally, a novel valuation approach based on the AHP has been proposed. The result shows that the value of Itaipu's energy in the Brazilian electricity market should be 106.73 USD/MWh under assumed assumptions, which would represent great benefits for Paraguay in many aspects.

\section{Key References}

Bellver, J. A., Martínez, F. G., \& Jiménez, J. M. (2007). Valoración agraria multicriterio en un entorno con escasa información. Estudios de Economía Aplicada, 25(2).

Guijarro, E., \& Guijarro, F. (2009). Valoración multicriterio de empresas: una aplicación al sector bodeguero español. Dirección y Organización, (39), 86-92.

Aznar, J., Ferrís-Oñate, J., \& Guijarro, F. (2010). An ANP framework for property pricing combining quantitative and qualitative attributes. Journal of the Operational Research Society, 61(5), 740-755.

Marques-Perez, I., Segura, B., \& Maroto, C. (2014). Evaluating the functionality of agricultural systems: Social preferences for multifunctional peri-urban agriculture. The "Huerta de Valencia" as case study. Spanish Journal of Agricultural Research, 12(4), 889-901. 